\begin{tabular}{l|l|l|l|l|l|l|l|l|l|}
\hline 1899 & Mittl. Ortsz. & $\Delta \alpha$ & $\Delta \delta$ & Vgl. & $\alpha$ app. & $\log p . \Delta$ & $\delta$ app. & $\log p . \Delta \mid$ Red. ad l. app. & $*$ \\
\hline
\end{tabular}

Am ro $1 / 2$ zöll. Refractor der Kgl. Sternwarte in München von Dr. W. Villiger.

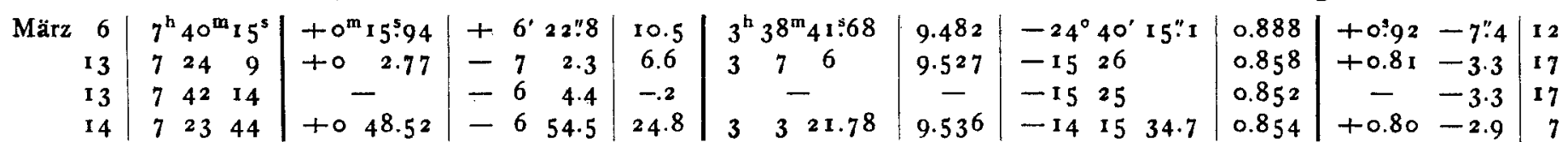

Am 6 zöll. Refractor der Sternwarte in Pola von Linienschiffsfähnrich A. Stupar.

März $6 \mid \begin{array}{lll}7 & 4 & \circ\end{array}$

Ringmikrometer, $r=718^{\prime \prime}$, Vergr. 50. Kern deutlich. Am 7. März wurde der Comet zu gleicher Zeit mit Sternen $8^{\mathrm{m}} \cdot \circ$ im Fernrohr sichtbar, konnte aber wegen eintretender Bewölkung nicht beobachtet werden.

A uf der Sternwarte in Padua von Dr. A. Antoniazzi.

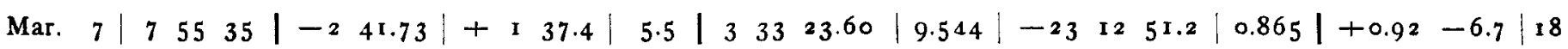
Auf der Privatsternwarte in Jena von Herrn W. Winkler.

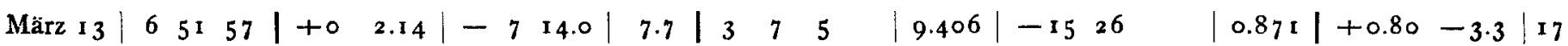
Comet rund, etwa $3^{\prime}$ Durchmesser.

Auf der Grossherzogl. Sternwarte in Jena von Prof. O. Knopf.

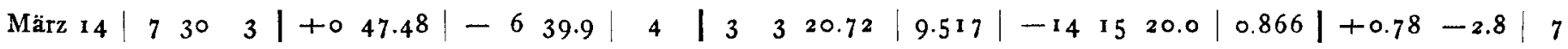

Am 6 zöll. Cometensucher der Sternwarte in Göttingen von Prof. L. Ambronn.

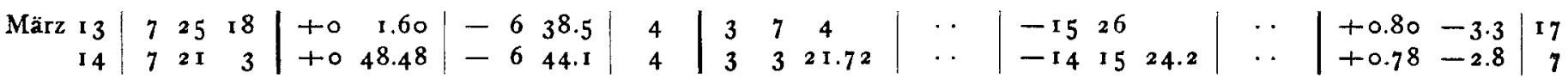

Kreuzstabmikrometer. - März I 3. Comet eine in der Mitte dichtere Nebelmasse von $3^{\prime}-4^{\prime}$ Durchmesser, kein

Schweif zu erkennen. - März r 4. Comet etwas heller als gestern, wegen tiefen Standes keine Details wahrzunehmen.

Telegramme an die Centralstelle.

I1. März $7^{\mathrm{h}} 7^{\mathrm{m}} \cdot \mathrm{O}$ Strassburg RA. app. $=4^{\circ} 4^{\circ} 6^{\prime} \times 5^{\prime \prime} \quad$ PD. app. $=107^{\circ} 5^{\prime 2} 29^{\prime \prime}$ Kobold. Becker.

12. 735.2 Hamburg $7444 \mathrm{12} \quad 106372$ Schorr.

Mittlere Oerter der Vergleichsterne.

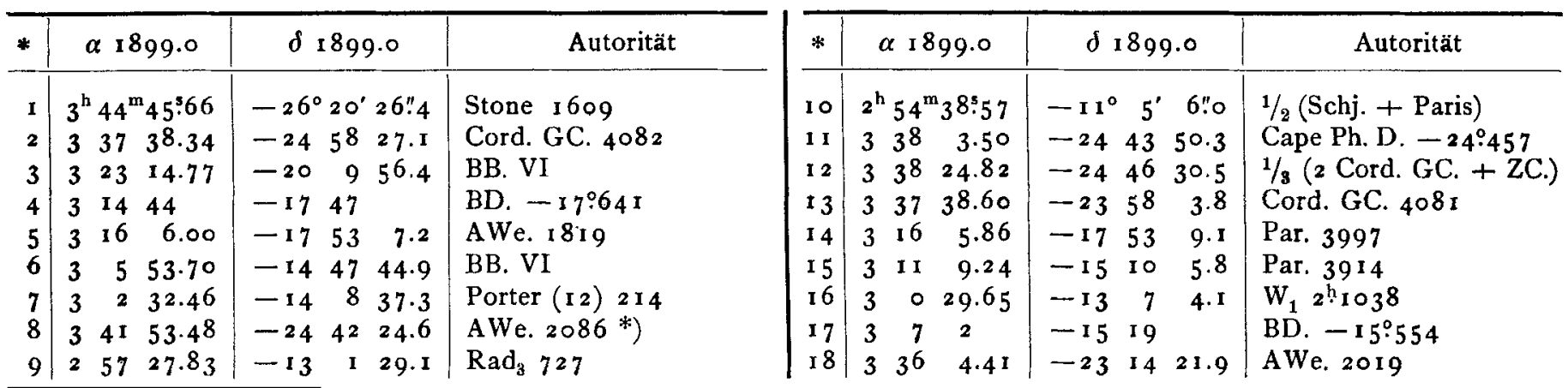

*) Prof. Abetti schätzt den Stern $5^{\mathrm{m}}-6^{\mathrm{m}}$, während er in Cord. DM., Cape Ph. D., AWe. als $8 \mathrm{~m} 5$ aufgeführt ist. Auch Dr. Hartwig ist am 6. März die grosse Helligkeit des vermuthlich veränderlichen Sterns aufgefallen. $K r$.

\title{
Beobachtung der Nova in Sagittarius von 1898.
}

Die Nova von Mrs. Fleming beobachtete ich am ${ }_{13}$. März $\mathbf{r}^{\mathrm{h}}{ }^{\mathrm{h}}{ }^{\mathrm{m}} \cdot{ }_{4} \mathrm{M}$. Z. Bamberg und bestimmte ihren Ort gegen

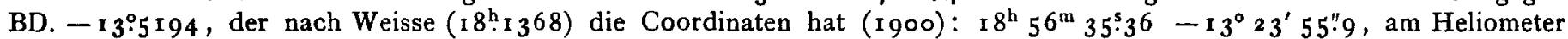
bei sehr schlechter Luft, woraus folgt

Nova (1900): $18^{\mathrm{h}} 56^{\mathrm{m}} 12^{\mathrm{s}} .69-13^{\circ} 18^{\prime} 22^{\prime \prime} 3$.

Die Helligkeit ist $10^{\mathrm{m}}$, nahe $1 / 2$ Grössenclasse schwächer als BD. $-13^{\circ} 5193\left(9^{\mathrm{m}} \cdot 5\right)$.

Bamberg, I 899 März I 4.

E. Hartwig. 